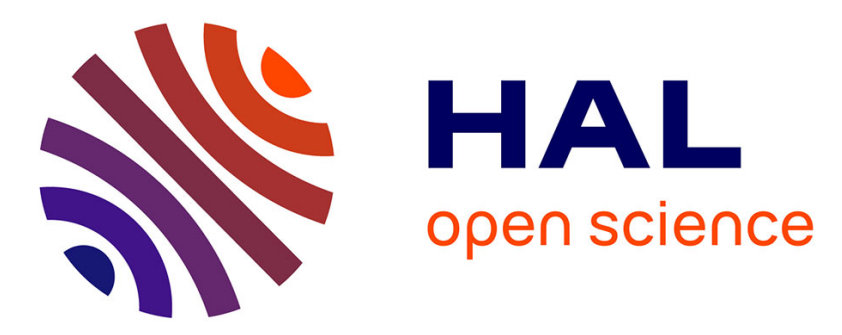

\title{
Explicit temperature-based model for anaerobic digestion: Application in domestic wastewater treatment in a UASB reactor
}

A Donoso-Bravo, H Satoh, G Ruiz-Filippi, Bandara W.M.K.R.T.W.

\section{- To cite this version:}

A Donoso-Bravo, H Satoh, G Ruiz-Filippi, Bandara W.M.K.R.T.W.. Explicit temperature-based model for anaerobic digestion: Application in domestic wastewater treatment in a UASB reactor. Bioresource Technology, 2013, pp.437-442. 10.1016/j.biortech.2013.01.174 . hal-01086016

\section{HAL Id: hal-01086016 https://hal.inria.fr/hal-01086016}

Submitted on 1 Jun 2021

HAL is a multi-disciplinary open access archive for the deposit and dissemination of scientific research documents, whether they are published or not. The documents may come from teaching and research institutions in France or abroad, or from public or private research centers.
L'archive ouverte pluridisciplinaire HAL, est destinée au dépôt et à la diffusion de documents scientifiques de niveau recherche, publiés ou non, émanant des établissements d'enseignement et de recherche français ou étrangers, des laboratoires publics ou privés. 


\begin{tabular}{|c|l|}
\hline Title & $\begin{array}{l}\text { Explicit temperature based model for anaerobic digestion: A pplication in domestic wastewater treatment in a UA SB } \\
\text { reactor }\end{array}$ \\
\hline Author(s) & Donoso-Bravo, A.; Bandara, W.M.K.R.T.W.; Satoh, Hisashi; Ruiz-Filippi, G. \\
\hline Citation & $\begin{array}{l}\text { Bioresource Technology, 133, 437-442 } \\
\text { https://doi.org/40.1016j.biortech.2013.01.174 }\end{array}$ \\
\hline Issue Date & 2013_04 \\
\hline Doc URL & http://hdl.handle.net/2115/52086 \\
\hline Type & article(author version) \\
\hline File Information & bt133_437-442.pdf \\
\hline
\end{tabular}

Instructions for use 


\title{
Explicit temperature-based model for anaerobic digestion.
}

\section{Application in domestic wastewater treatment in a UASB}

\section{reactor}

\author{
A. Donoso-Bravo ${ }^{1,2 *}$, W. M. K. R. T. W. Bandara ${ }^{3}$, H. Satoh ${ }^{3}$, G. Ruiz-Filippi ${ }^{1,2}$ \\ ${ }^{1}$ Escuela de Ingeniería Bioquímica, Pontificia Universidad Católica de Valparaíso. General Cruz 34, \\ Valparaíso, Chile. \\ ${ }^{2}$ INRIA-Chile. Chilean Informatics Research and Innovation Centre (CIRIC). Rosario Norte 555 of. 703 , Las \\ Condes, Santiago, Chile \\ ${ }^{3}$ Division of Environmental Engineering, Faculty of Engineering, Hokkaido University, North-13, West-8, \\ Sapporo 060-8628, Japan
}

(*author for correspondence: e-mail: andres.donoso@ucv.cl; phone: +56-32-2274178)

\begin{abstract}
Temperature is an important environmental variable that can strongly affect the performance of anaerobic reactors working at ambient temperatures. This study presents a mechanistic mathematical model which depends in an explicit way on the operating temperature. The cardinal temperature model function is proposed to describe the temperature dependence of the kinetic parameters and the experimental data from an UASB-degasification system was used to calibrate the model. The performance of the model is compared with the classic Arrhenius approach. The results showed that the
\end{abstract}


temperature-based model of the anaerobic digestion is able to reproduce a long-term reactor operation in terms of biogas production and the concentration of organic matter at fluctuating ambient temperature.

Key words: biogas; cardinal temperature model; membrane; modeling; UASB. 


\begin{tabular}{|c|c|c|c|}
\hline \multicolumn{4}{|c|}{ NOTATION } \\
\hline$S_{0}$ & $\begin{array}{lll}\text { Particulate } & \text { organic } & \text { matter } \\
\left(\mathrm{gCOD} \mathrm{L}^{-1}\right) & & \end{array}$ & $P_{T}$ & total pressure of the reactor (atm) \\
\hline$S_{1}$ & $\begin{array}{l}\text { Soluble organic matter (gCOD } \\
\left.\mathrm{L}^{-1}\right)\end{array}$ & $K_{H}$ & Henry's constant $\left(\mathrm{L}\right.$ atm mol$\left.{ }^{-1}\right)$ \\
\hline$S_{2}$ & $\begin{array}{l}\text { Acetic acid equivalent (gCOD } \\
\left.\mathrm{L}^{-1}\right)\end{array}$ & $R$ & Ideal gas constant $\left(\mathrm{L}\right.$ atm $\left.\mathrm{mol}^{-1} \mathrm{~K}^{-1}\right)$ \\
\hline$X_{1}$ & $\begin{array}{l}\text { Acidogens concentration } \\
\left(\mathrm{gCOD} \mathrm{L}^{-1}\right)\end{array}$ & $K_{a}$ & $\begin{array}{l}\text { Affinity constant of the reaction Acetic } \\
\text { acid/Acetate }\left(\mathrm{mol} \mathrm{L}^{-1}\right)\end{array}$ \\
\hline$X_{2}$ & $\begin{array}{l}\text { Methanogens concentration } \\
\left(\mathrm{gCOD} \mathrm{L}^{-1}\right)\end{array}$ & $k_{L} a$ & Volumetric mass transfer coefficient $\left(\mathrm{d}^{-1}\right)$ \\
\hline IC & Inorganic carbon $\left(\mathrm{mmol} \mathrm{L}^{-1}\right)$ & $\xi$ & State variable \\
\hline $\bar{Z}$ & Total alkalinity $\left(\mathrm{mmol} \mathrm{L}^{-1}\right)$ & $\xi_{\text {in }}$ & State variable value in the inlet \\
\hline$\alpha$ & Biomass retention parameter & $D$ & Dilution rate $\left(\mathrm{d}^{-1}\right)$ \\
\hline$r_{H}$ & Hydrolysis rate $\left(\mathrm{gCOD} \mathrm{L}^{-1} \mathrm{~d}^{-1}\right)$ & SRT & Solid retention parameter $(\mathrm{d})$ \\
\hline$r_{A}$ & Acidogenesis rate $\left(\mathrm{gCOD} \mathrm{L}^{-1} \mathrm{~d}^{-1}\right)$ & HRT & Hydraulic retention parameter $(\mathrm{d})$ \\
\hline$r_{M}$ & $\begin{array}{l}\text { Methanogenesis rate }(\mathrm{gCOD} \mathrm{L} \\
\left.{ }^{1} \mathrm{~d}^{-1}\right)\end{array}$ & $P$ & Temperature dependent parameter \\
\hline$Y_{X I}$ & Acidogens yield $\left(\mathrm{g} \mathrm{g}^{-1}\right)$ & $A$ & Frequency factor $\left(\mathrm{d}^{-1}\right)$ \\
\hline$Y_{X 2}$ & Methanogens yield $\left(\mathrm{g} \mathrm{g}^{-1}\right)$ & $E a$ & Activation energy \\
\hline
\end{tabular}




\begin{tabular}{|c|c|c|c|}
\hline $\begin{array}{l}f_{-} I C_{-} S 1 \\
f_{-} I C_{-} S 2\end{array}$ & $\begin{array}{l}\text { Stoichiometric coefficients of } I C \\
\text { production }\left(\mathrm{mmol} \mathrm{g}^{-1}\right)\end{array}$ & $P_{0}$ & $\begin{array}{l}\text { Optimum of Temperature dependent } \\
\text { parameter }\end{array}$ \\
\hline$k_{0}$ & hydrolysis coefficient $\left(\mathrm{d}^{-1}\right)$ & $T_{a b s}$ & Absolute temperature of the reactor $\left({ }^{\circ} \mathrm{K}\right)$ \\
\hline$K_{X}$ & $\begin{array}{l}\text { Contois half saturation constant } \\
\left(\mathrm{g} \mathrm{g}^{-1}\right)\end{array}$ & $T$ & Reactor temperature $\left({ }^{\circ} \mathrm{C}\right)$ \\
\hline$K_{S 1}$ & 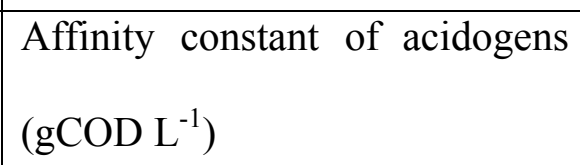 & $T_{\min }$ & $\begin{array}{l}\text { Minimum temperature of CTM model } \\
\left({ }^{\circ} \mathrm{C}\right)\end{array}$ \\
\hline$K_{S 2}$ & $\begin{array}{l}\text { Affinity constant of } \\
\text { methanogens }\left(\mathrm{gCOD} \mathrm{L}{ }^{-1}\right)\end{array}$ & $T_{\text {opt }}$ & $\begin{array}{l}\text { Optimum temperature of CTM model } \\
\left({ }^{\circ} \mathrm{C}\right)\end{array}$ \\
\hline$\mu_{m l}$ & $\begin{array}{l}\text { Maximum specific growth rate } \\
\text { of the acidogens }\left(\mathrm{d}^{-1}\right)\end{array}$ & $T_{\max }$ & $\begin{array}{l}\text { Maximum temperature of CTM model } \\
\left({ }^{\circ} \mathrm{C}\right)\end{array}$ \\
\hline$\mu_{m 2}$ & $\begin{array}{l}\text { Maximum specific growth rate } \\
\text { of the methanogens }\left(\mathrm{d}^{-1}\right)\end{array}$ & & \\
\hline
\end{tabular}




\section{Introduction}

The anaerobic treatment of domestic wastewater by using high rate reactors such as an UASB system, along with its new upgrades and modified versions, is expectable to keep growing in the coming years, above all, due to the fact the systems are more and more efficient and present a low carbon footprint in comparison with the traditional activated sludge systems (Chong et al. 2012).

Modeling is considered as a key tool especially for operational analysis, the development of control strategies and model-based design procedures. Thus far, application of models for anaerobic domestic wastewater treatment have been quite simple and applied at steady state conditions, in which one-reaction is recognized as the limiting step (Batstone 2006). Simplified mechanistic models may offer a good platform to both analyze, in some extent, the system behavior and evaluate some control and operational strategies.

Furthermore, in the case of low-strength wastewater when the non-linearity of the systems stands out, more complex kinetics should be considered for the system description. In these models, different variables, that exert a clear effect on some parameters, are usually considered, for instance: $\mathrm{pH}$, ammonia and inhibitors. Temperature is a crucial variable that clearly affects the performance of any anaerobic system. However, it has been barely considered in an explicit way for the model of anaerobic systems. The reason for this, is because the reactors for industrial wastewater treatment are normally operated at constantcontrolled temperatures (mesophilic $\left(35^{\circ} \mathrm{C}\right)$ or thermophilic $\left(55^{\circ} \mathrm{C}\right)$ ), thereby the influence 
of the temperature can be considered to be constant as well. For energetic and cost saving purposes the application of anaerobic digestion at ambient temperature has been studied for different substrates, especially for domestic or low-strength wastewater, where heating of high volumes to $35^{\circ} \mathrm{C}$ is unlikely (Bandara et al. 2012; Sumino et al. 2007; Bodik et al. 2002). Under these conditions there will be temperature fluctuations mainly due to smoother seasonal variations, day-night variations and also some specific spikes or drops events. Therefore, in such cases the temperature influence has to be considered as a part of any mathematical model trying to represent this particular system.

The effect of the temperature on kinetic parameters has been usually modeled by applying the classic Arrhenius model (Banik et al. 1998; Ge et al. 2011; Yuan et al. 2011), however the most important disadvantage of this equation is that is only able to reproduce the increasing part of the temperature influence on the parameter values, despite the fact the each of the microbial population, i.e. thermophils $\left(50-55^{\circ} \mathrm{C}\right)$, mesophils $\left(35-37^{\circ} \mathrm{C}\right)$ and psichrophils $\left(15-25^{\circ} \mathrm{C}\right)$ present a sharp drop in their activity after reached the optimum plateau (Pavlostathis and Giraldo-Gomez 1991). The cardinal temperature model (CTM) developed by Rosso et al. (1993) can describe the complete temperature influence profile and it has already been demonstrated its applicability in anaerobic digestion (Donoso-Bravo et al. 2009).

The aim of this study is to develop a mathematical model of the anaerobic digestion process which considers the temperature effect in an explicit way as an integrated part of the model conception. Then, the results of the model by using the classical Arrhenius 
approach and the proposed CTM are compared. The model is calibrated and validated with an upflow anaerobic sludge blanket reactor treating domestic sewage at ambient temperature.

\section{Material and methods}

\subsection{Experimental system}

The lab system from where the experimental data was taken for this modeling application corresponds to UASB reactor treating domestic wastewater, coupled with a membrane reactor for degasification and recovery of the dissolved methane from the effluent. A thorough description of the system can be found in (Bandara et al. 2012). In Figure 1 the input conditions to which the system was subjected are shown in terms of organic load rate (OLR) and temperature, during nearly a year and a half. Reactor temperature was not controlled presenting a seasonal variation from 5 to $30^{\circ} \mathrm{C}$ in winter and summer respectively, while OLR was in the range of 1 to $3 \mathrm{gCOD} \mathrm{L}^{-1} \mathrm{~d}^{-1}$. During the one and a half year operation, measurements, on a daily basis, were taken for $\mathrm{CH}_{4}$ flow, $\mathrm{CO}_{2}$ flow and chemical oxygen demand, particulate (pCOD) and soluble (sCOD).

\subsection{Mathematical model}

Different kind of modeling approaches can be found in the literature for UASB reactors. Simple mechanistic models of the anaerobic degradation process have been used either using one global reaction representation of the system (Bhunia and Ghangrekar 2008), two reactions (Lopez and Borzacconi 2009) or approaches with three populations and reactions 
(Vlyssides et al., 2007). Although mechanistic models are normally preferred, other approaches have also been used, for instance, empirical models obtained by using polynomial regression (Barampouti et al., 2005) as well as steady state based procedures (Yetilmezsoy 2012). In this study, a three reactions and two populations model of the anaerobic digestion process was used. These types of models have been lately used as alternatives to large and more descriptive models of the bioprocess (Donoso-Bravo et al., 2010; Mairet et al. 2012). A Petersen Matrix of the model representation can be seen in Table 1. The mass balance of the system is shown in eq. 1 .

$$
\frac{d \xi_{i}}{d t}=D \cdot\left(\xi_{i n, i}-\xi_{i}\right)+\sum_{j=3} a_{j} r_{i, j}-q_{c}
$$

The right-side term represents the sum of the kinetic rate process $j$, described by multiplication of their stoichiometric coefficient $a$, and the reaction rate $r$. This sum is represented in a Petersen matrix form, in Table 1 . In regards to the reaction rates, the Contois expression is used to describe the hydrolytic reaction (Mairet et al. 2012; Ramirez et al. 2009) because it better explains the hydrolysis phenomena since it takes both the substrate and biomass concentrations into account. The Monod function is considered for both the acidogenesis and methanogenesis reaction. In the case of the methanogenesis due to the fact that the concentration of acetic acid will never reach an inhibitory level under this conditions, thereby there is a lack of experimental solicitation to estimate the parameter, a Monod function was chosen instead of, for instance, a Haldane-type function. 
As in UASB reactor the solid retention time is much higher than the hydraulic retention time (HRT) a parameter $\alpha$, which is the inverse of the HRT, multiplies the biomass term in equation 1 . This simple way of considering biomass retention in the reactor was originally presented by Bernard et al. (2001).

One of the main model assumptions is that all the methane generated in the degradation process goes to the gas phase and none remains soluble in the liquid phase. Despite this assumption is not valid when low-strength wastewater are being treated, this assumption holds in our case since the degasification units coupled to the UASB reactor recuperated most of the solubilized biogas. Methane (eq. 2), $\mathrm{CO}_{2}$ (eq. 3) and pH (eq. 4) can be expressed as functions of some of the state variables:

$$
q_{M}=k_{6} r_{2}
$$

$q_{C}=k_{L} a\left(I C+S_{2}-Z-K_{H}\left(\frac{\varphi-\sqrt{\varphi^{2}-4 K_{H} P_{T}\left(I C+S_{2}-Z\right)}}{2 K_{H}}\right)\right)$

where $\varphi=I C+K_{H} P_{T}+\frac{q_{M}}{k_{L} a}$

$$
p H=-\log \left(K a \frac{I C+S_{2}-Z}{Z-S_{2}}\right)
$$




\subsection{Explicit modeling of the temperature influence}

In this study, three of the kinetic parameters; the hydrolysis coefficient and the maximum specific growth rates of acidogens and methanogens $\left(k_{0}, \mu_{m 1}\right.$ and $\left.\mu_{m 2}\right)$ are not longer considered constant but instead as function of the temperature by using the Arrhenius (eq. 5) and CTM (eq. 6) model, as described below:

$$
P=A \cdot \exp \left(-E a / R \cdot T_{a b s}\right)
$$

$$
P=P_{0} \cdot \frac{\left(T-T_{\max }\right)\left(T-T_{\min }\right)^{2}}{\left(T_{o p t}-T_{\min }\right)\left[\left(T_{o p t}-T_{\min }\right) \cdot\left(T-T_{o p t}\right)-\left(T_{o p t}-T_{\max }\right) \cdot\left(T_{o p t}+T_{\min }-2 T\right)\right]}
$$

In the case of CTM, and due to the number of model parameters in regard to the measured outputs, $\mathrm{T}_{\min }, \mathrm{T}_{\max }$ and $\mathrm{T}_{\mathrm{opt}}$ were assumed to be the same for hydrolysis, acidogenesis and methanogenesis, although, $P_{o}$ was independently calibrated for each process. This reduces from 9 temperature-related parameters to 3 , to be calibrated, and is reasonable assumption in practice, since in previous researches, separate estimation of $\mathrm{T}_{\min }$, $\mathrm{T}_{\max }$ and $\mathrm{T}_{\mathrm{opt}}$ for each process, showed that these values are similar to each other (DonosoBravo et al 2009). This simplification was needed, since separate estimation demands more specific experimentation and an extensive experimental design. 
The model without temperature dependence was used as a control simulation since the results obtained under this condition are only influenced by the variation of the organic load rate that enters the system.

\subsection{Model calibration and validation}

The whole operation period was divided two periods. In each of them the parameter estimation and the cross-validation were performed with two different set of data. For parameter calibration, four experimental variables were used: $\mathrm{CH}_{4}$ flow, $\mathrm{CO}_{2}$ flow, sCOD (eq. 7) and pCOD (eq. 8). The latest variables can be related to the experimental data through the following equations:

$$
\begin{aligned}
& s C O D=S_{1}+S_{2} \\
& p C O D=t C O D-s C O D=S_{0}+X_{1}+X_{2}
\end{aligned}
$$

A direct-search procedure based on the Nelder-Mead algorithm is used to explore the parameter space. In this case, the least-squares criterion (eq. 8), was used as the minimization criterion.

$$
J(\theta)=\min \sum_{t=1}^{N}\left(y_{\exp }(t)-y_{\text {sim }}(t, \theta)\right)^{2}
$$


where $J$ is the objective function, $y_{\text {exp }}$ is the obtained from measurements, $y_{\text {sim }}$ is the corresponding simulated value, $\theta$ represents the parameters to be determined and $\mathrm{N}$ is the number of measurements.

In order to compare the temperature model response the sum of squared error (SSE) that measures the total deviation of the experimental values from the model fit, is used and shown in eq. 10.

$$
S S E_{i}=\frac{1}{N} \sqrt{\sum_{t=1}^{N}\left(y_{\text {exp }}(t)-y_{\text {sim }}(t, \theta)\right)^{2}}
$$

The model implementation, calibration and validation were carried out in Matlab ${ }^{\circledR}$.

\section{Results and discussion}

\subsection{Comparison between temperature-based functions}

The comparison of the models performance is shown in Figure 2, where it can be seen that by using CTM function, the model behaviour improves compared to both the control and the Arrhenius-based model. A steady enhancement of the model prediction, expressed as SSE, is obtained with CTM for both the calibration and the validation period, except for the pCOD prediction, which does not show any kind of improvement. This must be due to the large variability of the pCOD measurement in comparison to the other variables. With regard to the Arrhenius-based model, results show that there is no a significant improvement of using this model instead of the control one. It was expected to have a 
unsatisfactory results with both Arrhenius and control however it was important to know for how much the use of CTM function could improve the overall model behaviour.

The best obtained model fit (with calibrated parameters) of the control, the Arrhenius-based model and the CTM, with roughly 1.5-years of experimental data, is shown in Figure 3, for the gas outputs and the organic matter. It is clearly observed that neither the Arrhenius-based approach nor the control model can reproduce the behaviour of the reactor, especially in the case of the gases production profiles. As observed, CTM performs much better than the Arrhenius-based model thereby the onward discussion is only about the results obtained with CTM.

\subsection{Performance of CTM}

Concerning the performance of CTM-based anaerobic model, and in regards to $\mathrm{CH}_{4}$ and $\mathrm{CO}_{2}$, overall the model is able to describe the reactor behaviour in both calibration and validation period, thereby this temperature-functions and the model chosen may be used as a way to predict and estimate the biogas production at a changing ambient temperature. It worth to point out that this explicit temperature model can cope with fluctuations of the temperature of around $25^{\circ} \mathrm{C}$ of difference that were observed during this evaluation period. Small ranges of temperature variations were evaluated by Merlin et al. (2012) who used a simply steady state model in an UASB reactor treating warm dairy wastewater and assessed the influence of the heat transfer with the environment. 
In a more in-depth analysis, some disagreements between the model prediction and the experimental values are however observed. For instance, despite both the model and the reactor show a null biogas production up until day $100^{\text {th }}$, the model overestimates the $\mathrm{CH}_{4}$ production between day 100 and $150^{\text {th }}$. This increment is related to a temperature rise (Figure 1), to which the system did not show the same response. This may be due to some delay in the recovery of the microorganisms, which is not considered in the present model application.

Concerning the organic matter degradation profiles, the model reproduces the general trend of the pCOD despite this experimental data shows an important dispersion during the evaluation period. This is totally understandable due to the low concentration that we are dealing with, as well as the intrinsic error of the experimental method which becomes more relevant at these conditions. Nevertheless, the model performance is appropriate in terms of the process behaviour. In regards to the sCOD, the model performance is outstanding since it mimics the dynamic of the variable along the whole system operation. Here it can be seen the importance of the experimental error which in case of sCOD is much less than pCOD. Despite this model assumes that all the volatile fatty acids behaves as acetic acid, which corresponds to one of the main simplifications of the model, this does not have any negative effect on the model prediction of the soluble COD. This assumption has shown to be have a bigger impact on the model performance when substrate with a higher concentration of organic matter have been used (DonosoBravo et al. 2012) 


\subsection{Parameter calibration of CTM}

As a first comment, it has to be highlighted that in general very few studies that aim the estimation of kinetic parameters in anaerobic digestion with domestic wastewater can be found in literature. Therefore, a more complete comparison of the parameters values cannot be easily done. It is worth to point out, the fact that the low-strength characteristic of the domestic wastewater makes possible the estimation of the affinity constants. The latter is not usually done due to when dealing with substrates with a high concentration organic matter, for instance, sewage sludge or organic fraction of municipal solid waste, the kinetic is driven in the surroundings of the maximum growth rates of the biomass.

In regards to the procedure itself, several optimization runs were carried, starting off from different initial guesses of the parameters in order to minimize the probability of getting trapped in local minima. In this context, some parameters estimation problems were observed, above all, with $\mathrm{T}_{\min }$ and $k_{o}$, since neither a lower nor an upper bound of the values could be determined, respectively. The calibrated values for $\mathrm{T}_{\mathrm{opt}}$ and $\mathrm{T}_{\max }$ are around the expected values for mesophilic biomass. The Contois half saturation constant has only been estimated for sewage sludge degradation; however, the obtained value in the present study is similar to those (Mairet et al. 2012; Tomei et al. 2008). The affinity constant of the acidogens is greater than the typical reported values, which may be due to the fact the soluble fraction of domestic wastewater is more recalcitrant than the conventional high strength substrates (Orhon and Okutman 2003). However, for methanogens, the affinity constant agrees with the common values (Siegrist et al 2002; Batstone et al 2002). The yield values are also according to what has been reported, with a low biomass yield for the 
methanogens than the acidogens. An interesting result was the obtained value for $\alpha$ which gives an idea of the SRT of the reactor. As expected the obtained SRT is around 1000-fold greater that the HRT, which demonstrated the capacity of the system to retain the biomass in the reactor. Table 2 presents all the calibrated parameter values.

A more in-depth discussion about the parameter values cannot be done since the calibration of parameters does not correspond to an identification procedure itself which is normally performed under more controlled conditions and using a more specific experimental design. In addition, the results of an identification procedure must be presented along with a statistical analysis (e.g. confidence intervals, standard deviation). In any case, the calibrated values provide a certain idea about the real values of the parameters.

\section{Conclusion}

A simplified mechanistic model explicit in temperature dependency for the anaerobic treatment of domestic wastewater at ambient temperature was implemented and validated with lab scale UASB-membrane system. The CTM-based model was able to properly cope with the seasonal changes of temperature and predict the general behavior of the system, showing better results than the conventional Arrhenius approach. Cardinal temperature model may be used as a dynamic function for representing the parameters dependence to the operating temperature

\section{Acknowledgements}


Andres Donoso-Bravo is supported by the "Dirección de Investigación (DII)" of the Pontificia Universidad Católica de Valparaíso

\section{References}

1. Bandara, W. M. K. R., Kindaichi, T., Satoh, H., Sasakawa, M., Nakahara, Y., Takahashi, M., Okabe, S. 2012. Anaerobic treatment of municipal wastewater at ambient temperature: Analysis of archaeal community structure and recovery of dissolved methane. Water Res. 46, 5756-64.

2. Banik, G.C., Viraraghavan, T., Dague, R.R. 1998. Low temperature effects on anaerobic microbial kinetic parameters. Environ. Technol. 19, 503-512

3. Barampouti, E. M. P., Mai, S. T., Vlyssides, A. G. 2005. Dynamic modeling of biogas production in an UASB reactor for potato processing wastewater treatment. Chem. Eng. J. 106, 53-58.

4. Batstone, D. J., Keller, J., Angelidaki, I., Kalyuzhnyi, S. V., Pavlostathis, S. G., Rozzi, A., Sanders, W. T., Siegrist, H., and Vavilin, V. A. (2002). Anaerobic digestion model no. 1. (ADM1). Iwa Task Group,IWA Task Group for Mathematical Modelling of Anaerobic Digestion Processes., IWA Publishing, London.

5. Batstone, D. J., 2006. Mathematical modelling of anaerobic reactors treating domestic wastewater: Rational criteria for model use. Rev. Environ. Sci. Biotechnol. 5, 57-71.

6. Bernard, O., Hadj-Sadok, Z., Dochain, D., Genovesi, A., Steyer, J. P., 2001. Dynamical model development and parameter identification for an anaerobic wastewater treatment process. Biotechnol. Bioeng. 75, 424-438. 
7. Bhunia, P., Ghangrekar, M. M. 2008. Analysis, evaluation, and optimization of kinetic parameters for performance appraisal and design of UASB reactors. Bioresour. Technol. 99, 2132-2140.

8. Bodik, I., Herdova, B., Drtil, M. 2002. The use of upflow anaerobic filter and AnSBR for wastewater treatment at ambient temperature. Water Res. 36, 1084-1088.

9. Chong, S., Sen, T. K., Kayaalp, A., and Ang, H. M. 2012. The performance enhancements of upflow anaerobic sludge blanket (UASB) reactors for domestic sludge treatment - A State-of-the-art review. Water Res. 46, 3434-3470.

10. Donoso-Bravo, A., Mailier, J., Ruiz-Filippi, G., Vande Wouwer, A. 2012. Identification in an anaerobic batch system: global sensitivity analysis, multi-start strategy and optimization criterion selection. Bioprocess Biosyst. Eng. 36, 35-43.

11. Donoso-Bravo, A., Retamal, C., Carballa, M., Ruiz-Filippi, G., Chamy, R. 2009. Influence of temperature on hydrolysis, acidogenesis and methanogenesis in anaerobic digestion: parameter identification and modeling application. Water Sci. Technol. 60, 9-17.

12. Ge, H., Jensen, P. D., Batstone, D. J. 2011. Relative kinetics of anaerobic digestion under thermophilic and mesophilic conditions. Water Sci. Technol. 64, 848-853.

13. Lopez, I., Borzacconi, L. 2009. Modelling a full scale UASB reactor using a COD global balance approach and state observers. Chem. Eng. J., 146, 1-5.

14. Mairet, F., Bernard, O., Cameron, E., Ras, M., Lardon, L., Steyer, J. P., Chachuat, B. 2012. Three-reaction model for the anaerobic digestion of microalgae. Biotechnol. Bioeng. 109, 415-425. 
15. Merlin, G., Kohler, F., Bouvier, M., Lissolo, T., Boileau, H. 2012. Importance of heat transfer in an anaerobic digestion plant in a continental climate context. Bioresour. Technol. 124, 59-67.

16. Orhon, D., Okutman, D. 2003. Respirometric assessment of residual organic matter for domestic sewage. Enzym. Microb. Tech. 32, 560-566.

17. Pavlostathis, S. G., Giraldo-Gomez, E. 1991. Kinetics of anaerobic treatment: A critical review. CRC Crit. Rev. Environ. Contr. 21, 411-490.

18. Ramirez, I., Mottet, A., Carrere, H., Deleris, S., Vedrenne, F., and Steyer, J. P. (2009). Modified ADM1 disintegration/hydrolysis structures for modeling batch thermophilic anaerobic digestion of thermally pretreated waste activated sludge. Water Research, 43, 3479-3492.

19. Rosso, L., Lobry, J. R., Flandrois, J. P. 1993. An Unexpected Correlation Between Cardinal Temperatures of Microbial-Growth Highlighted by A New Model. J.Theor. Biol. 162, 447-463.

20. Siegrist, H., Vogt, D., Garcia-Heras, J., and Gujer, W. (2002). Mathematical model for meso- and thermophilic anaerobic sewage sludge digestion. Environ Sci Technol, 36, 1113-1123.

21. Sumino, H., Takahashi, M., Yamaguchi, T., Abe, K., Araki, N., Yamazaki, S., Shimozaki, S., Nagano, A., Nishio, N. 2007. Feasibility study of a pilot-scale sewage treatment system combining an up-flow anaerobic sludge blanket (UASB) and an aerated fixed bed (AFB) reactor at ambient temperature. Bioresour. Technol. 98, 177182. 
22. Tomei, M. C., Braguglia, C. M., and Mininni, G. 2008. Anaerobic degradation kinetics of particulate organic matter in untreated and sonicated sewage sludge: Role of the inoculum. Bioresour. Technol. 99, 6119-6126.

23. Vlyssides, A., Barampouti, E., Mai, S. 2007. Effect of Ferrous Ion on the Biological Activity in a UASB Reactor: Mathematical Modeling and Verification. Biotechnol. Bioeng, 96, 853-861.

24. Yetilmezsoy, K. 2012. Integration of kinetic modeling and desirability function approach for multi-objective optimization of UASB reactor treating poultry manure wastewater. Bioresour. Technol. 118, 89-101.

25. Yuan, Q., Sparling, R., Oleszkiewicz, J. A. 2011. VFA generation from waste activated sludge: Effect of temperature and mixing. Chemosphere. 82, 603-607. 
Table 1. Petersen matrix

\section{$\begin{array}{lllllll}\text { State variable } \rightarrow S_{0} & S_{1} & S_{2} & X_{1} & X_{2} & \text { IC } & \text { Reaction rate }\end{array}$}

\section{Process}

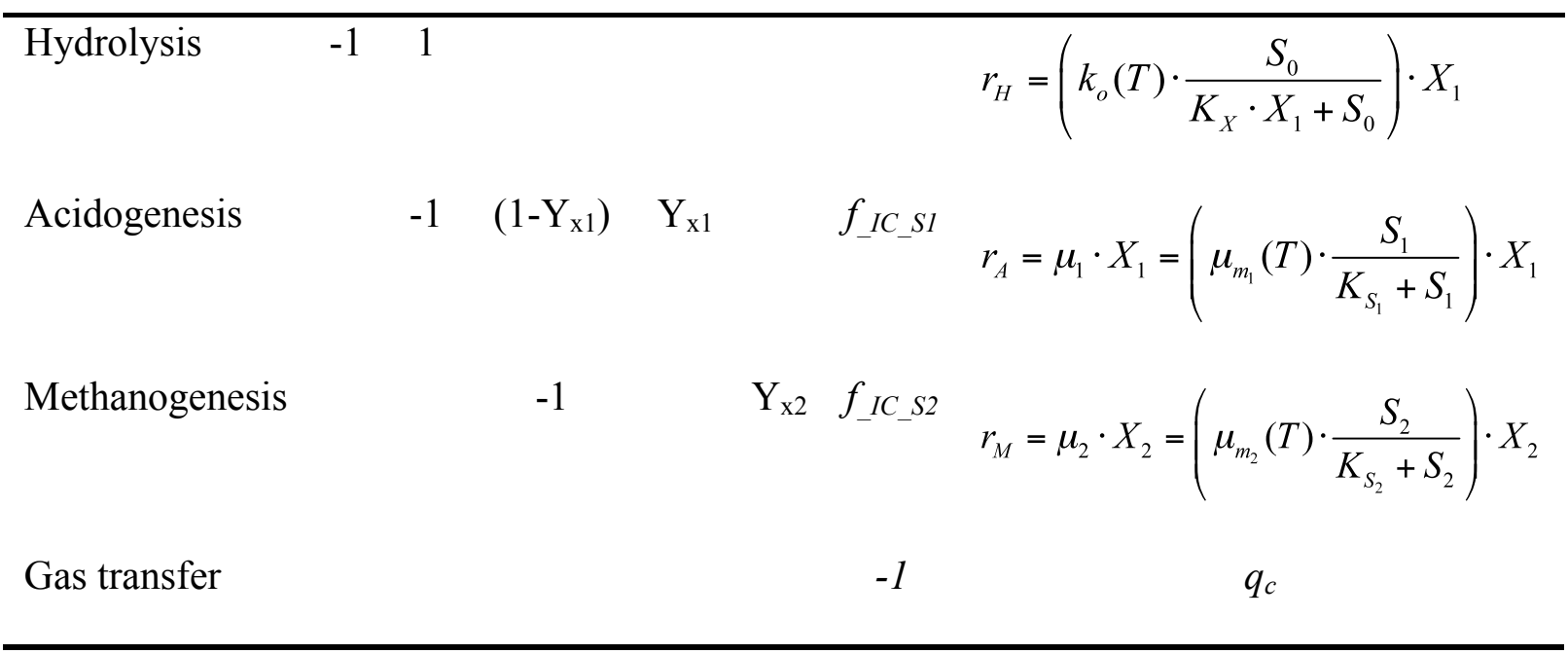


Table 2. Parameters calibrated values

\begin{tabular}{|c|c|c|c|c|c|}
\hline Parameter & Value & unit & Parameter & value & unit \\
\hline$T_{\min }$ & $<5$ & ${ }^{\circ} \mathrm{C}$ & $\overline{K_{X}}$ & 1.38 & $\mathrm{~g} \mathrm{~g}^{-1}$ \\
\hline$T_{\max }$ & 40.1 & ${ }^{\circ} \mathrm{C}$ & $K_{s 1}$ & 1.68 & $\mathrm{~g} \mathrm{~L}^{-1}$ \\
\hline$T_{\text {opt }}$ & 33.1 & ${ }^{\circ} \mathrm{C}$ & $K_{s 2}$ & 0.06 & $\mathrm{~g} \mathrm{~L}^{-1}$ \\
\hline$k_{0 \_0}$ & $>50$ & $\mathrm{~d}^{-1}$ & $Y_{x 1}$ & 0.46 & $\mathrm{~g} \mathrm{~g}^{-1}$ \\
\hline$\mu_{m 1 \_0}$ & 12.9 & $\mathrm{~d}^{-1}$ & $Y_{x 2}$ & 0.02 & $\mathrm{~g} \mathrm{~g}^{-1}$ \\
\hline$\mu_{m 2 \_}$ & 3.6 & $\mathrm{~d}^{-1}$ & $\alpha$ & 0.001 & - \\
\hline
\end{tabular}




\section{Figure captions}

Figure 1. Input conditions of the experimental UASB-membrane system in terms of temperature (grey points) and organic load rate (black points)

Figure 2. (a) Comparison of the results among the control model (blue), the Arrheniusbased model (red) and CTM model (green), in terms of SSE (b) Percentage of SSE reduction by using CTM-based model compared to control model (white circles) and Arrhenius-based model (black squares).

Figure 3. Gas production profiles and organic matter concentration during calibration and validation. Experimental data (black points), control model (red solid line), Arrheniusbased model (green solid line), CTM based model (blue solid line). 


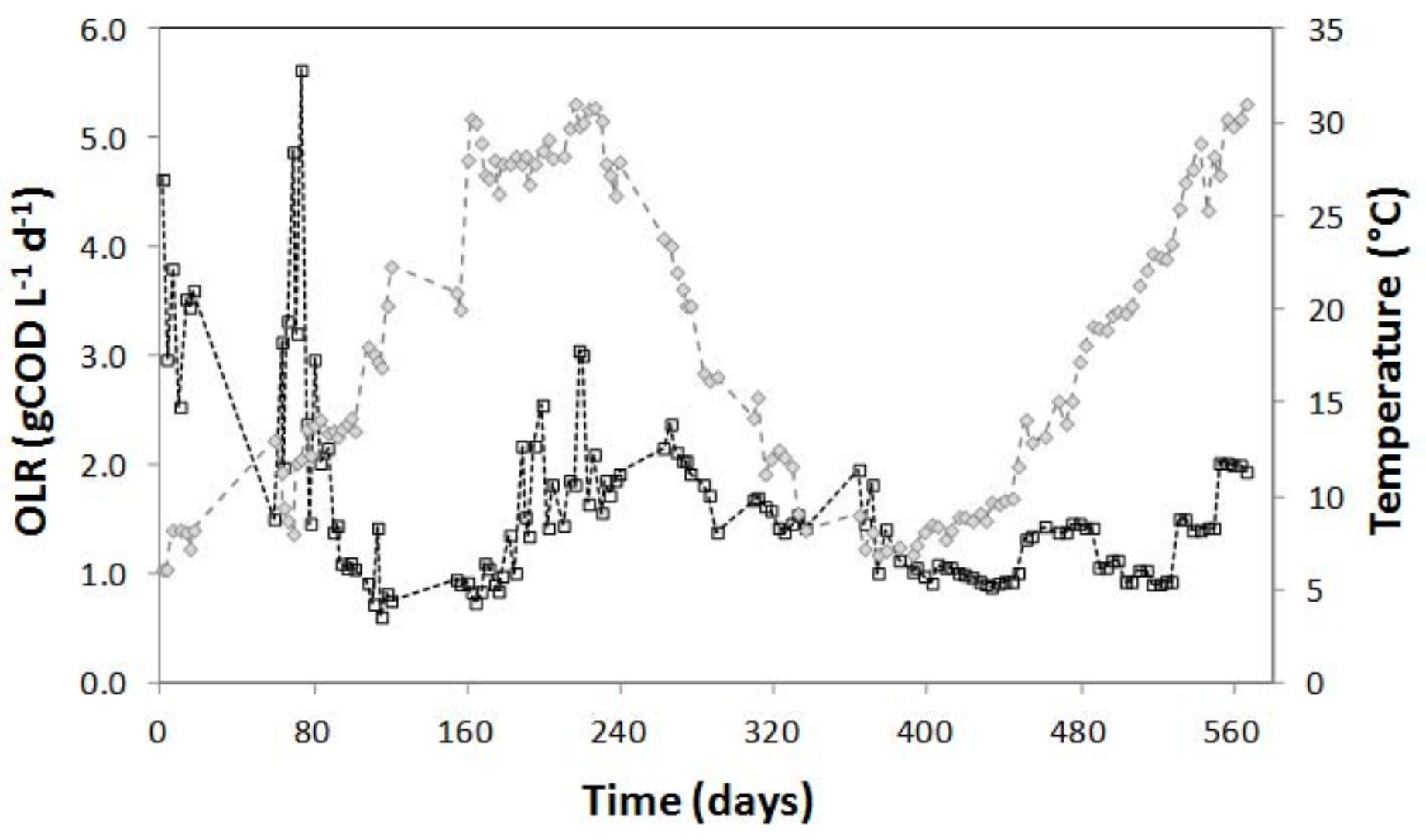



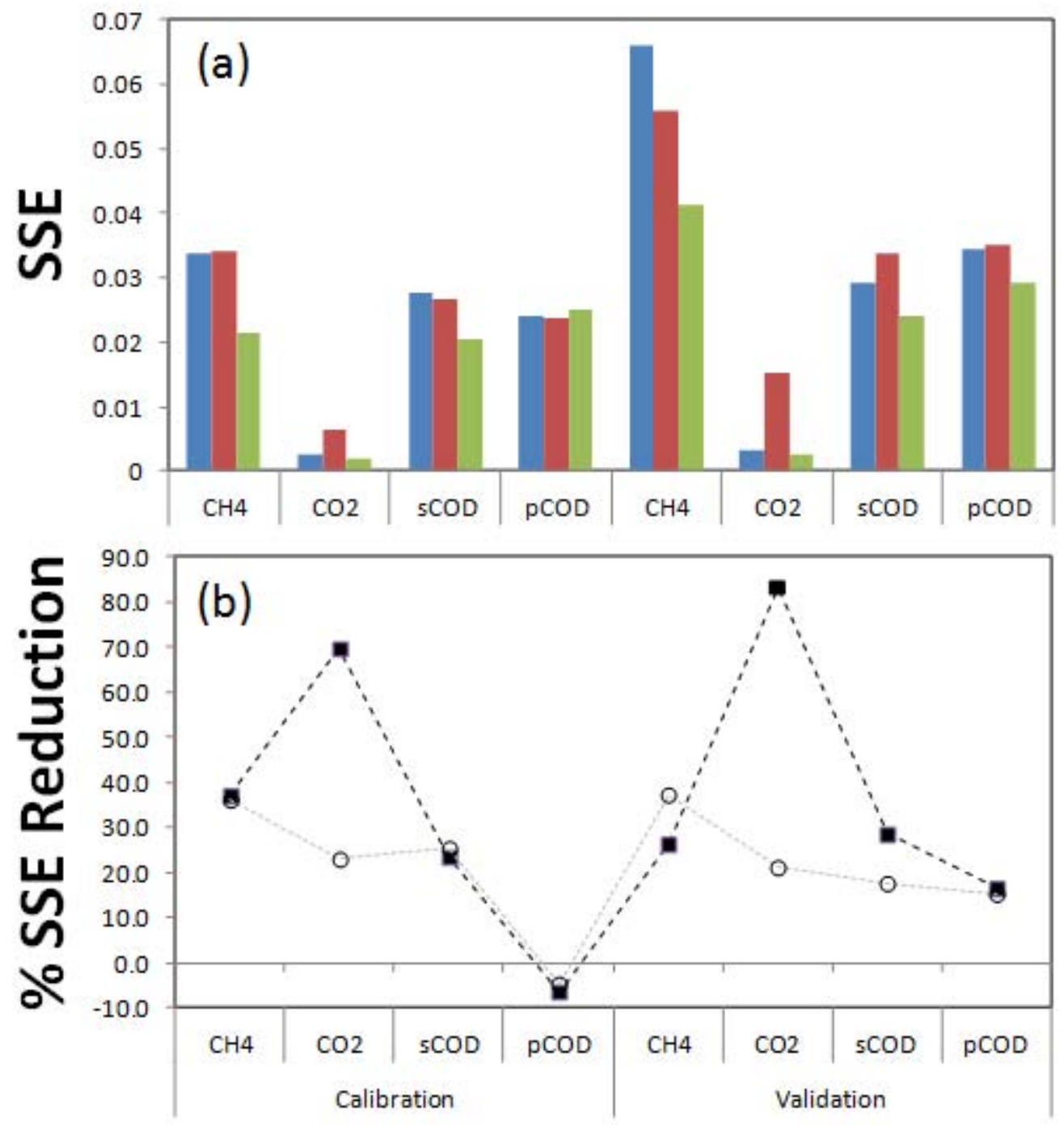

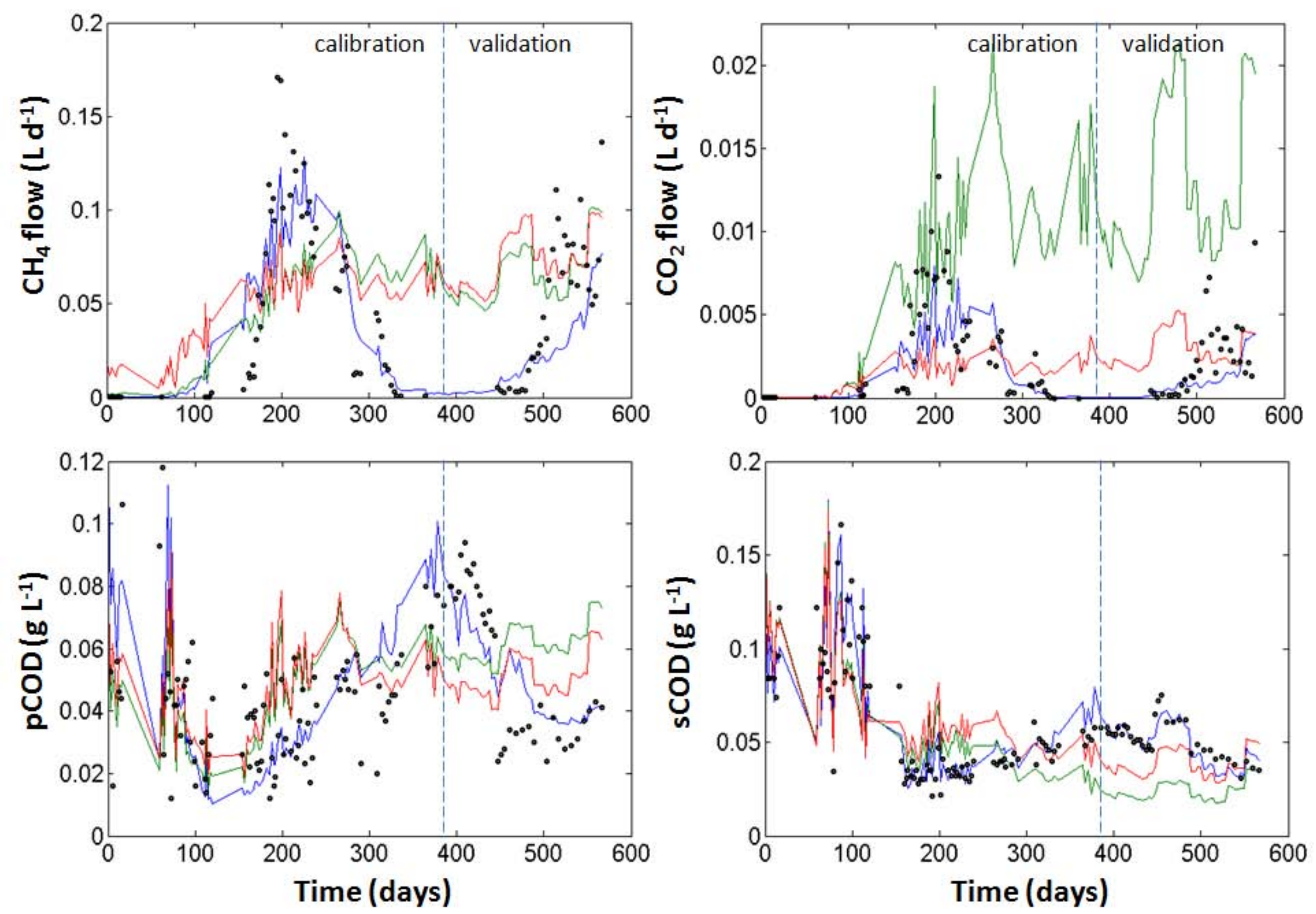